\section{Bioactivity of Extracts of Foeniculum vulgare and Ocimum basilicum against Heterotermes indicola (Wasmann)}

\author{
Ayesha Aihetasham ${ }^{1, *}$, Muhammad Saeed Akhtar', Maryam Umer ${ }^{1}$, \\ Khalid Zamir Rasib ${ }^{2}$ and Muhammad Imran Din $^{3}$ \\ ${ }^{1}$ Department of Zoology, University of the Punjab, Lahore-54590, Pakistan \\ ${ }^{2}$ FC College University, Ferozepur Road, Lahore, Pakistan \\ ${ }^{3}$ Institute of Chemistry, University of the Punjab, Lahore-54590, Pakistan
}

\begin{abstract}
A B S T R A C T
As Heterotermes indicola (Wasmann) is known to cause considerable damage to wood work in buildings. Efficacy of extracts of Foeniculum vulgare and Ocimum basilicum was studied against this termite. Chemical composition of plant extracts by chromatography-mass spectrometry (GC-MS) revealed five different compounds in F. vulgare: Piperidine, 3-isopropyl, Bicyclo[2.2.1]heptan-2-one, 1,3,3-trimethyl, Benzaldehyde, 4-methoxy, Estragole, 11-Octadecenoic acid, methyl ester and 9-Octadecenoic acid ethyl ester. Whereas nine different compounds were identified in extracts of $O$. basilicum. These were: 1-Isopropyl-2, 2-dimethylpropylideneamine, Camphor, Naphthalene, Thymol, 1,5,5- Trimethyl-6-x methylene-cyclohexene, Hexadecanoic acid, methyl ester, 9,12,15 Octadecatrienoic acid, methyl ester, 8, 11, 14-Eicosatrienoic acid and 1,2-Benzenedicarboxylic acid, mono(2-ethylhexyl) ester. Extracts of both the plants were found repellent to this termite. $\mathrm{LT}_{50}$ values of $O$. basilicum and $F$. vulgare against Heterotermes indicola were 60.91 and $115.9 \mathrm{~h}$, respectively.
\end{abstract}
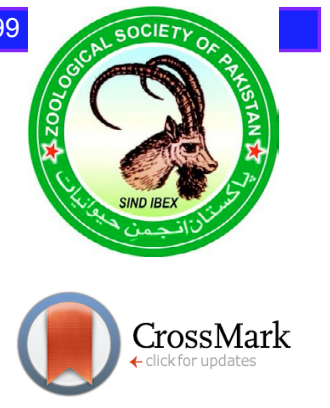

\begin{tabular}{l} 
Article Information \\
\hline Received 06 June 2017 \\
Revised 26 July 2017 \\
Accepted 07 August 2017 \\
Available online 22 November 2017 \\
Authors' Contribution \\
AA and MSA designed the project and \\
supervised the work. MU performed \\
the experimental work. AA helped \\
in the collection of data. KZR and \\
MID helped in the execution of the \\
experimental work. AA and MID \\
helped in handling the data. MU, AA \\
and MSA wrote the article. \\
Key words \\
Bioactivity, Foeniculum vulgare, GC- \\
MS, Ocimum basilicum, Heterotermes \\
indicola.
\end{tabular}

\section{INTRODUCTION}

$\mathrm{T}$ ermites are abundant in tropical region and are very devastating to wood (Harris, 1971; Ajayi et al., 2012). Heterotermes spp. are structure-infesting termites that account for a significant proportion of damage wherever they occur and are confined to their respective climatic zones by the limits of soil moisture and temperature (Emerson, 1971; Saljoqi et al., 2012).

With the increasing spread of termite infestation, there is an increased need to find out human and environment safe treatments (Meepagala et al., 2006). Many attempts have been made in the field and in the laboratory to exploit the termite activity by plant extracts. Some plant species have been used in the past to explore its anti- termite activity (Adams et al., 1988). There is a growing interest in natural toxic substances from plants (Chang et al., 2001; Elango et al.,2012). Secondary metabolites like alkaloids, chromenes, coumarins and terpenoids, especially monoterpenoids are produced by the plants for their defense mechanism. These secondary metabolites have been evaluated for their domestic pests controlling properties. Attention towards

\footnotetext{
Corresponding author: misswaqar@yahoo.com 0030-9923/2017/0006-2193 \$ 9.00/0

Copyright 2017 Zoological Society of Pakistan
}

oils was renewed in the 1990s with increasing expression of their fumigant and contact insecticidal activities for an extensive array of insects (Isman, 2000; Koul et al., 2008).

The harmful effects of phytochemicals against insects are manifested in numerous ways like inhibition of calling behavior (Khan and Saxena, 1986; Ahmed et al., 2011), delayed growth (Breuer and Schmidt, 1995; Ahmed et al., 2011), toxicity (Hiremath et al., 1997; Ahmed et al., 2011), avoidance of oviposition (Zhao et al., 1998; Ahmed et al., 2011), suppression in feeding (Wheeler and Isman, 2001; Ahmed et al., 2011) and drop of fertility (Muthukrishnan and Pushpalatha, 2001; Ahmed et al., 2011).

Present studies were undertaken to assess the toxic potential of the extracts of $F$. vulgare (fennel) and $O$. basilicum (niazbo) against $H$. indicola. Our objectives were (i) ethanolic extraction of selected plant seeds using soxhlet extractor and (ii) structural characterization of compounds of seeds extracts through GC-MS.

\section{MATERIALS AND METHODS}

\section{Collection of termites}

Termite workers and soldiers of species $H$. indicola (Wasmann) were collected from old trees of Populus euramericana from Lahore. The termites were maintained for at least 1 week on water soaked filter papers and $5 \mathrm{~g}$ 
oven dried soil in each Petri-plate.

\section{Seeds collection}

Seeds of locally used medicinal plants, $F$. vulgare (Saunf/Fennel) and O. basilicum (Niazbo) were purchased from local market.

\section{Preparation of extracts}

The seeds of the medicinal plants were ground into fine powder using a grinder. Twenty grams of each seed powder was taken separately for extraction in Soxhlet extractor with $200 \mathrm{ml}$ of ethanol. Rotary evaporator was used to obtain dried residues and stored in refrigerator for making stock solution. Stock solution was prepared for each plant extract by taking $1 \mathrm{~g}$ dried extract in $10 \mathrm{ml}$ of absolute ethanol to get a solution of $10 \%$ concentration. Concentrations used were $10 \%, 5 \%$ and $3 \%$.

\section{Gas chromatography/mass spectrometry}

All seed samples were analyzed by gas chromatography coupled with mass spectrometry. The gas chromatography conditions include a temperature range of 50 to $250^{\circ} \mathrm{C}$ with $4^{\circ} \mathrm{C} / \mathrm{min}$, with a solvent delay of 5 $\min$. The temperature of injector was maintained at $250^{\circ} \mathrm{C}$.
Helium was used as an inert gas with a flow rate of $1.0 \mathrm{~mL} /$ min. and the volume of injected sample in the split less mode was $2 \mu \mathrm{L}$. The MS conditions were the following: ionization energy, $70 \mathrm{eV}$; quadrupole temperature $100^{\circ} \mathrm{C}$; scanning velocity, 1.6 scans/s; weight range, 40-500 amu.

The percent composition of the samples was calculated. The qualitative analysis was based on the percent area of each peak of the sample compounds. The mass spectrum of each compound was compared with the mass spectrum from the spectra library NIST 98 (USA National Institute of Science and Technology software).

\section{Anti-termitic assay}

Circular filter papers were cut and placed at the bottom of each sterilized glass Petri plate. Each filter paper was soaked with $0.5 \mathrm{ml}$ of the $10 \%, 5 \%$ and $3 \%$ extracts concentrations. Petri plates containing filter paper were dried at ambient temperature. Fifty workers and five soldiers of $H$. indicola were added in each Petri plate. Observations were taken after every $2 \mathrm{~h}$ up to $12 \mathrm{~h}$. Data for the mortality of the termite were recorded after an interval of $12 \mathrm{~h}$ up to $96 \mathrm{~h}$.

Mortality rate $\%=\frac{\text { No. of dead termites after test }}{\text { No. of initial termites used in test }} \times 100$

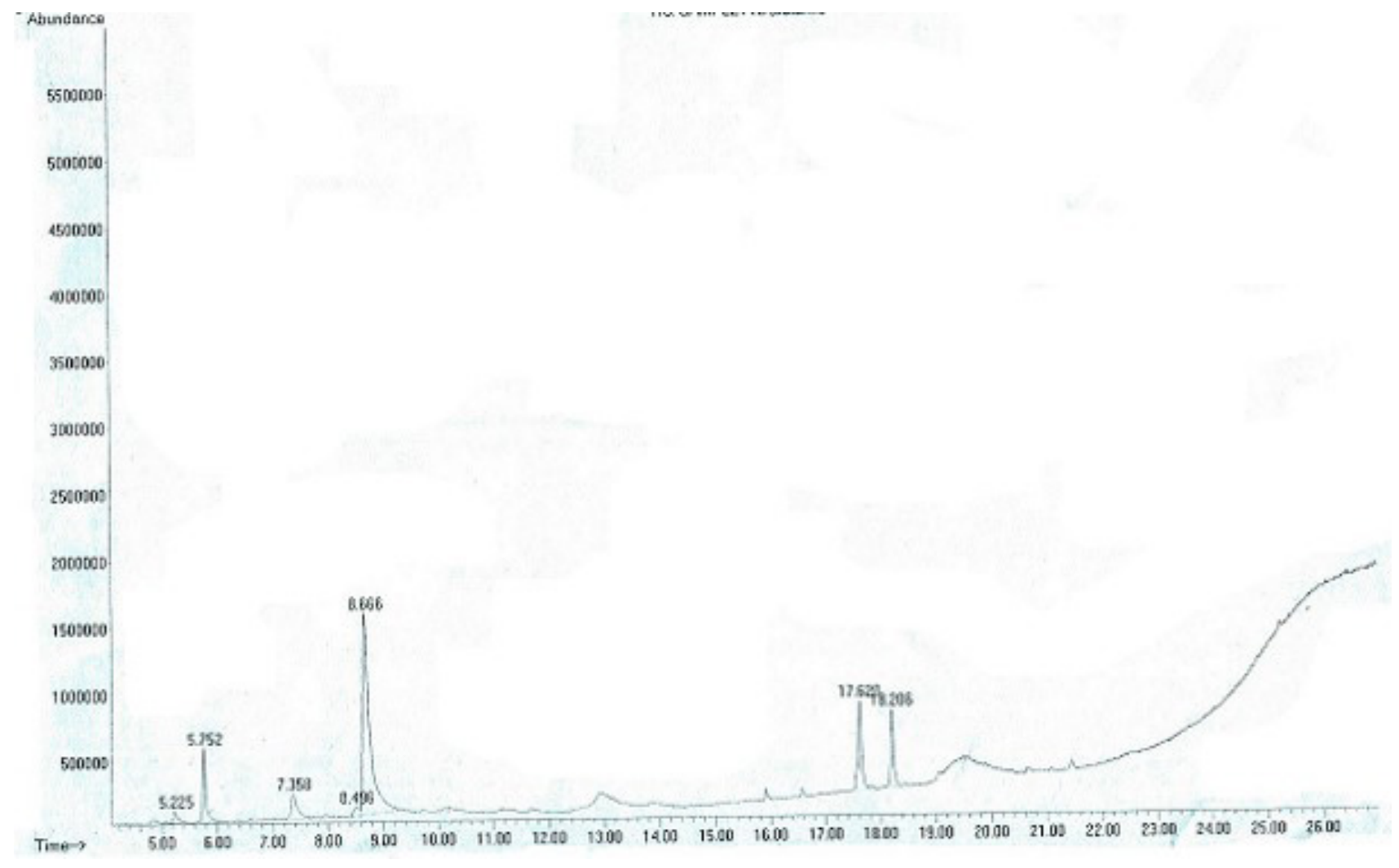

Fig. 1. Compounds identified by GC-MS analysis in F. vulgare. 
Table I.- Phytocompounds identified in ethanolic extract of $F$ : vulgare.

\begin{tabular}{|c|c|c|c|}
\hline $\begin{array}{l}\text { Retention time } \\
\text { Ninutes }\end{array}$ & Phytocompounds & $\begin{array}{c}\text { Relative percentage } \\
\text { composition }(\%)\end{array}$ & Structural formulae \\
\hline 5.225 & Piperidine, 3-isopropyl & 3.79 & \\
\hline 5.752 & Bicyclo[2.2.1]heptan-2-one, 1,3,3-trimethyl & 14.63 & \\
\hline 7.358 & Estragole & 12.35 & \\
\hline 8.496 & Benzaldehyde, 4-methoxy & 4.19 & \\
\hline 8.666 & Estragole & 100 & \\
\hline 17.620 & 11-Octadecenoic acid, methyl ester & 20.84 & \\
\hline 18.206 & 9-Octadecenoic acid ethyl ester & 15.09 & \\
\hline
\end{tabular}

\section{Repellency assay}

For the estimation of repellency filter papers of $9 \mathrm{~cm}$ in diameter were cut into two equal halves. One half of each filter paper was treated with $10 \%, 5 \%$ and $3 \%$ concentration of extracts and second half was treated with distilled water (untreated). The two halves were placed into the Petri dishes with a cut space in the middle. A total of 10 termites were released into the middle space. Repellency was noted after every 15 min by counting the number of termites on treated (T) and untreated (UT) filter paper discs and experiment was conducted for $2 \mathrm{~h}$. Three replicates were prepared for each concentration of all four plant extracts. A treatment concentration was considered repellent when 21 (sum of three replicates) of 30 termites were present on untreated filter paper for five consecutive readings.

\section{Statistical analysis}

Mortality percentage of termites was calculated and analyzed by using one way Anova values of $\mathrm{P}<0.05$ were considered significant statistically. $\mathrm{LT}_{50}$ was calculated by using Probit analysis (Finney, 1971).

\section{RESULTS AND DISCUSSION}

Extracts of $F$. vulgare and $O$. basilicum which are well known for their medicinal importance had an impact of termite survival also. $\mathrm{LT}_{50}$ value of termites exposed to extracts of $O$. basilicum was $60.91 \mathrm{~h}$; and the extract was also repellent. Extracts of $F$. vulgare was slightly less effective with $\mathrm{LT}_{50}$ value as $115.9 \mathrm{~h}$. But, its extract has also termite repellent attribute.

As regard Chemical composition/GC-MS analysis of the extract of $F$. vulgare revealed the presence of piperidine, bicyclo[2.2.1]heptan-2-one, estragole, benzaldehyde, 11-octadecenoic acid and 9-octadecenoic acid (Fig. 1, Table I). The least termiticidal effect was found in F. vulgare which was $37 \%$ against $H$. indicola. Foeniculum vulgare Mill commonly called fennel has been used in traditional medicine for a wide range of ailments related to digestive, endocrine, reproductive, and respiratory systems. Foeniculum vulgare remains to be the most widely used herbal plant. It has been used for more than forty types of disorders. Phytochemical studies have shown the presence of numerous valuable compounds, such as volatile compounds, flavonoids, phenolic compounds, fatty acids, and amino acids. Data indicate their efficacy in several in vitro and in vivo pharmacological properties such as antimicrobial, antiviral, antiinflammatory, antimutagenic, antinociceptive, antipyretic, antispasmodic, antithrombotic, apoptotic, cardiovascular, chemomodulatory, antitumor, hepatoprotective, hypoglycemic, hypolipidemic, and memory enhancing property (Badgujar et al., 2014). Abbas et al. (2013) conducted the study on EtOH extracts of fifteen medicinal plant seed which showed excellent antitermitic activity and the $\mathrm{LT}_{50}$ of Foeniculum vulgare, Peganum harmala, Psoralea corylifolia, Ricinus communis, Croton tiglium, Mentha species, $O$. sativum and Capsicum frutescens was found lower than $10 \mathrm{~h}$. 


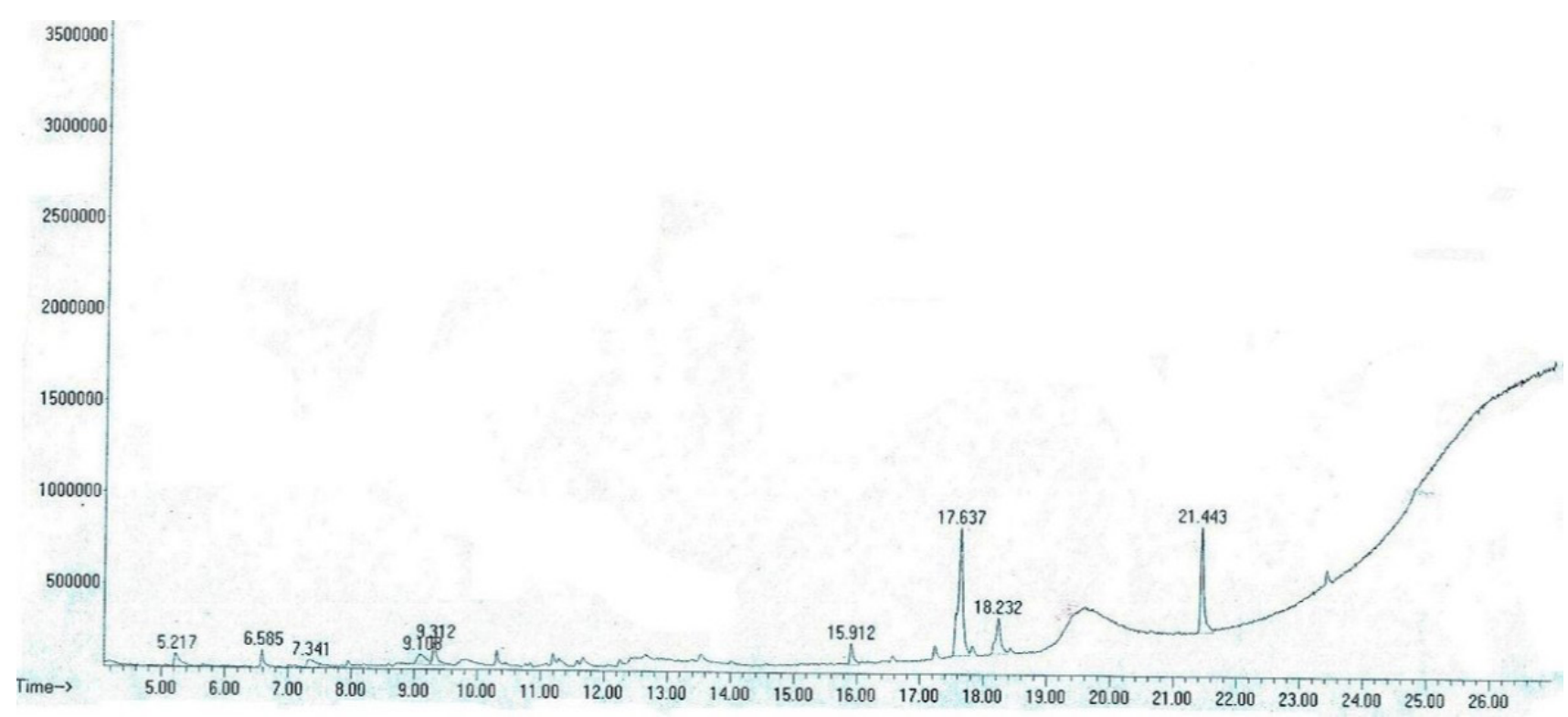

Fig. 2. Compounds identified by GC-MS analysis in O. basilicum.

Table II.- Phytocompounds identified in ethanolic extract of $O$. basilicum.

\begin{tabular}{|c|c|c|c|}
\hline $\begin{array}{l}\text { Retention time } \\
\text { Minutes }\end{array}$ & Phytocompounds & $\begin{array}{c}\text { Relative percentage } \\
\text { composition (\%) }\end{array}$ & Structural formulae \\
\hline 5.217 & 1-Isopropyl-2, 2-dimethylpropylideneamine & 11.82 & \\
\hline 6.585 & Camphor & 9.40 & \\
\hline 7.341 & Naphthalene & 11.73 & \\
\hline 9.108 & Thymol & 14.56 & \\
\hline 9.312 & 1,5,5-Trimethyl-6-methylene-cyclohexene & 15.02 & \\
\hline 15.912 & Hexadecanoic acid, methyl ester & 12.32 & \\
\hline 17.637 & $9,12,15$-Octadecatrienoic acid, methyl ester & 100 & \\
\hline 18.232 & $8,11,14$-Eicosatrienoic acid & 30.03 & \\
\hline 21.443 & 1,2-Benzenedicarboxylic acid, mono(2-ethylhexyl) esters & 56.51 & \\
\hline
\end{tabular}

The GCMS analysis of $O$. basilicum revealed the presence of components such as dimethylpropylamine, camphor, naphthalene, thymol, methylene cyclohexene, hexadecanoic acid, octadecatrienoic acid, eicosatrienoic acid and benzene dicarboxylic acid as shown in Figure 2 and
Table II. A related study was conducted by Govindarajan et al. (2013) on the toxicity of mosquito larvicidal activity of leaf essential oil and their major chemical constituents from Ocimum basilicum against Culex tritaeniorhynchus, Aedes albopictus and Anopheles subpictus. GC-MS revealed that 
the essential oil of $O$. basilicum contained 20 compounds. The major chemical components identified were linalool $(52.42 \%)$, methyl eugenol $(18.74 \%)$ and 1,8 -cineol (5.61\%). The essential oil had a significant toxic effect against late third-stage larvae of $C x$. tritaeniorhynchus, Ae. albopictus and An. subpictus with an $\mathrm{LC}_{50}$ values of 14.01, 11.97 and $9.75 \mathrm{ppm}$ and an $\mathrm{LC}_{90}$ values of 23.44, 21.17 and $18.56 \mathrm{ppm}$, respectively. The active ingredients in the essential oils were separated and identified by TLC and GC-MS in a study conducted by Nour et al. (2012) essential oils from two basil ( $O$. basilicum) accessions were tested in a laboratory bioassay for larvicidal activity against third instar A. aegypti larvae. Approximately 13 compounds $(>1 \%)$ were detected; most compounds were oxygenated monoterpenes. Linalool, geraniol, geranial, methyl chavicol and eugenol were active components against $A$. aegypti larvae.

The studied extracts of $O$. basilicum and $F$. vulgare contained biological active compound which showed greater potential against $H$. indicola. Control was established as preliminary test to check the termiticidal function of extracts with distilled water filter papers. Control was non toxic as most of the termites were remained alive for long time. Subsequently lethal time was determined as $\mathrm{LT}_{50}$ by Probit analysis. In our findings, O. basilicum showed high anti termitic activity with $\mathrm{LT}_{50}$ of $10 \%, 5 \%$ and $3 \%$ concentrations as $60.91,121.2$ and $154.6 \mathrm{~h}$, respectively. $83 \%$ termites were killed in $10 \%$ concentration of $O$. basilicum which was reduced in $F$. vulgare to $37 \%$. $\mathrm{LT}_{50}$ of $F$. vulgare extracts was 115.9 , 162.6 and $184.7 \mathrm{~h}$, respectively as shown in Figure 3.

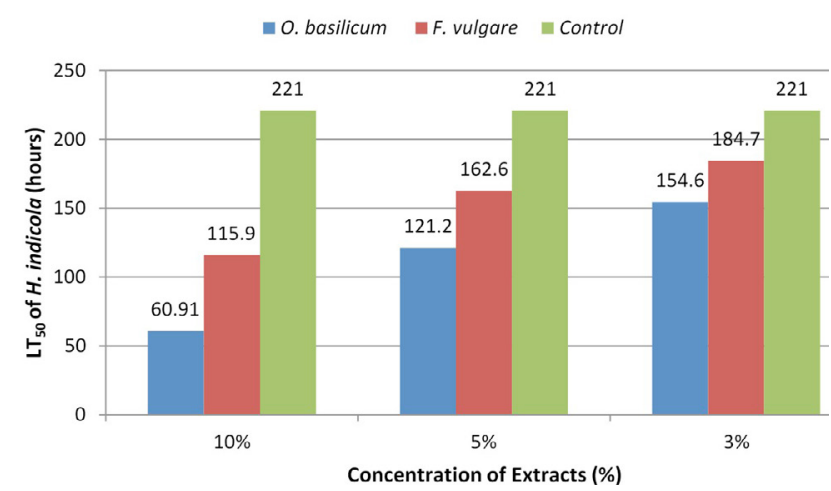

Fig. 3. $\mathrm{LT}_{50}$ of all concentrations of Extracts against $H$. indicola.

When termite workers exposed to $10 \%, 5 \%$ and $3 \%$ concentrations of $O$. basilicum along with untreated filter papers. Result showed that 3\% concentration was non repellent to $H$. indicola as less than 21 termites were present on untreated filter paper while $10 \%$ and $5 \%$ concentrations were found to be repellent, however all concentrations of F. vulgare i.e. $10 \%, 5 \%$ and $3 \%$ were repellent against $H$. indicola as shown in Figure 4.

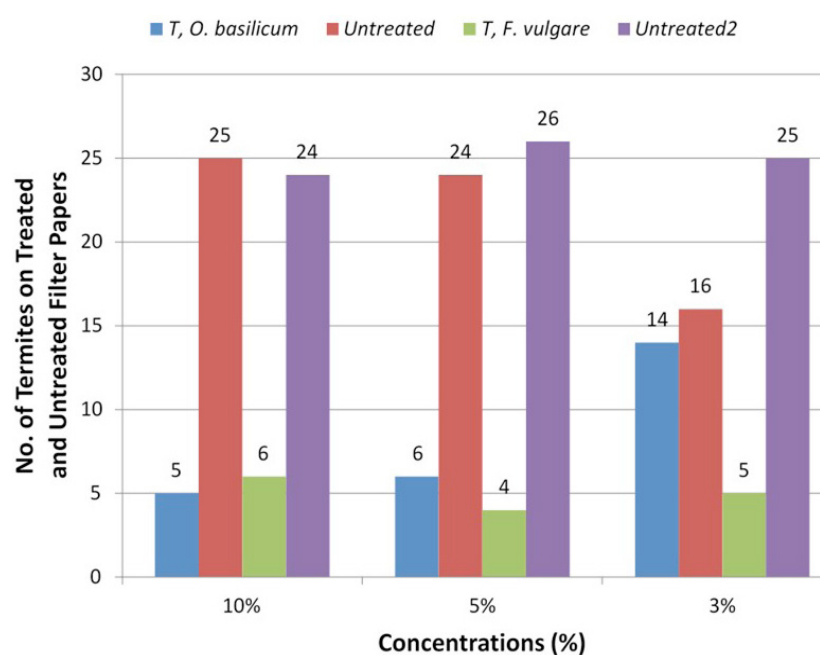

Fig. 4. Repellency test of $O$. basilicum and F. vulgare against $H$. indicola.

Termites as being devastating organisms to the wood and related products, a variety of techniques have been used to control them; the use of artificial pesticides is the most common practice. These chemicals are suspect to be absolutely effective against termites, however, they proved to be obstinate in nature and become part of our food chain thereby leading to process of magnification. If there are any leakages after heavy rain these insecticides cause serious environmental hazards (Logan et al., 1990; Martius, 1998; Jamil et al., 2005; Qureshi et al., 2012). Many attempts have been made in field and laboratory to exploit anti termitic activities of plants extracts. Some plant species were used in past to explore their anti-termite activities, insecticidal properties and anti-feedant activities and contain certain chemicals that reduce termite growth or kill them (Adams et al., 1988; Qureshi et al., 2015). In this study the toxic potential of $O$. basilicum and $F$. vulgare was investigated against $H$. indicola.

Ethanol extracts of $F$. vulgare and $O$. basilicum have a potential to be used for termite control. Both the extracts were found toxic against $H$. indicola

\section{CONCLUSION}

Ethanol extracts of $F$. vulgare and $O$. basilicum have a potential to be used for termite control. Both the extracts were found toxic against $H$. indicola. Likewise, these extracts must also be tried against termite species in different ecological zones of Pakistan for understanding 
better control and management of other termite species.

\section{ACKNOWLEDGEMENTS}

We are grateful to the Department of Zoology, University of the Punjab, Lahore, Pakistan for providing laboratory facilities for research work which is greatly appreciated and acknowledged.

\section{Statement of conflict of interest}

The authors declare that there is no conflict of interests regarding the publication of this article.

\section{REFERENCES}

Abbas, M., Shahid, M., Iqbal, M., Anjum, F., Sharif, S., Ahmed, S. and Pirzada, T., 2013. Antitermitic activity and phytochemical analysis of fifteen medicinal plant seeds. J. Med. Pl. Res., 7: 16081617.

Adams, R.P., McDaniel, C.A. and Carter, F.I., 1988. Termiticidal activities in the heartwood, bark/ sapwood and leaves of Junipers species from the United States. Biochem. Sys. Ecol., 16: 453-456. https://doi.org/10.1016/0305-1978(88)90043-9

Ahmed, S., Hussain, A., Zafar, M.I., Riaz, M.A. and Shahid, M., 2011. Evaluation of plant extracts on mortality and tunneling activities of subterranean termites in Pakistan. In: Pesticides in the modern world - Pests control and pesticides exposure and toxicity assessment (ed. M. Stoytcheva). INTECH Open Access Publisher. Available at: https://www. intechopen.com/books/pesticides-in-the-modernworld-pests-control-and-pesticides-exposure-andtoxicity-assessment

Ajayi, O.E., Adedire, C.O. and Lajide, L., 2012. Evaluation of partially purified fractions of crude extracts of the leaves of Morinda lucida (Benth.) and Datura stramonium (L.) for suppression of wood damage by subterranean termites. J. agric. Sci., 4: 125. https://doi.org/10.5539/jas.v4n5p125

Badgujar, S.B., Patel, V. and Bandivdekar, A., 2014. Foeniculum vulgare Mill: A review of its botany, phytochemistry, pharmacology, contemporary application, and toxicology. BioMed Res. Int., 2014: Article ID 842674.

Breuer, M.G.H. and Schmidt, G.H., 1995. Influence of a short period treatment with Melia azedarach extract on food intake and growth of the larvae of Spodoptera frugiperda (Lepidoptera; Noctuidae). J. Pl. Dis. Prot., 102: 633-654. https://doi. org/10.1155/2014/842674
Chang, S.T., ChenG, S.S. and Wang, S.Y., 2001. Antitermitic activity of essential oils and components from Taiwania (Taiwania cryptomerioides). J. chem. Ecol., 27: 1267-1274. https://doi.org/10.1023/A:1010397801826

Elango, G., Rahuman, A.A., Kamaraj, C., Bagavan, A., Zahir, A.A., Santhoshkumar, T. and Rajakumar, G., 2012. Efficacy of medicinal plant extracts against Formosan subterranean termite, Coptotermes formosanus. Ind. Crops Prod., 36: 524-530. https:// doi.org/10.1016/j.indcrop.2011.10.032

Emerson, A.E., 1971. Tertiary fossil species of the Rhinotermitidae (Isoptera) phylogeny, and reciprocal phylogeny of associated Flagellata (Protozoa) and the Staphylinidae (Coleoptera). Bull. Am. Mus. nat. Hist., 146: 243-304.

Finney, D.J., 1971. Probit analysis, 3rd edn. Cambridge University, London, UK, pp. 333.

Govindarajan, M., Sivakumar. R., Rajeswary, M. and Yogalakshmi, K., 2013. Chemical composition and larvicidal activity of essential oil from Ocimum basilicum (L.) against Culex tritaeniorhynchus, Aedes albopictus and Anopheles subpictus (Diptera: Culicidae) Exp. Parasitol., 134: 7-11. https://doi. org/10.1016/j.exppara.2013.01.018

Harris, W.V., 1971. Termites, their recognition and control. Longman Green and Co. Ltd., London, pp. 174.

Hiremath, I.G., Youngjoon, A., Soonll, K., Ahn, Y.J.L. and Kim, S.I., 1997. Insecticidal activity of Indian plant extracts against Nilaparvata lugens (Homoptera: Delphacidae). Appl. Ent. Zool., 32: 159-166. https://doi.org/10.1303/aez.32.159

Isman, M.B., 2000. Plant essential oils for pest and disease management. Crop Prot., 19: 603-608. https://doi.org/10.1016/S0261-2194(00)00079-X

Jamil, K., Shaik, A.P., Mahboob, M. and Krishna, D., 2005. Effect of organ phosphorus and organochlorine pesticides (Monochrotophos, Chlorpyriphos, Dimethoate, and Endosulfan) on human lymphocytes in vitro. Drug Chem. Toxicol., 27: 133-144. https://doi.org/10.1081/DCT120030725

Khan, Z.R. and Saxena, R.C., 1986. Effect of steam distillate extracts of resistant and susceptible rice cultivars on behaviour of Sogatella furcifera (Homoptera: Delphacidae). J. econ. Ent., 79: 928935.

Koul, O., Walia, S. and Dhaliwal, G.S., 2008. Essential oils as green pesticides: Potential and constraints. Biopest. Int., 4: 63-84.

Logan, J.W.M., Cowie, R.H. and Wood, T.G., 1990. 
Termite (Isoptera) control in agriculture and forestry by non-chemical methods: A review. Bull. entomol. Res., 80: 309-330. https://doi.org/10.1017/ S0007485300050513

Martius, C., 1998. Perspectives for the biological control of termite (Insecta, Isoptera). Rev. Brasil. Ent., 41: 179-194.

Meepagala, K.M., Osbrink, W., Sturtz, G. and Lax, A., 2006. Plant-derived natural products exhibiting activity against formosan subterranean termites (Coptotermes formosanus). Pest Manage. Sci., 62: 565-570. https://doi.org/10.1002/ps.1214

Muthukrishnan, J. and Pushpalatha, E., 2001. Effects of plant extracts on fecundity and fertility of mosquitoes. J. appl. Ent., 125: 31-35.

Nour, A.H., Yusoff, M.M. and Sandanasamy, J.D.O., 2012. Bioactive compounds from basil (Ocimum basilicum) essential oils with larvicidal activity against Aedes aegypti larvae. Int. Proc. chem. biol. environ. Engin., 46: 21-24.

Qureshi, N.A., Ashraf, A., Afzal, M., NaseerUllah, Iqbal, A. and Haleem, S., 2015. Toxic potential of Melia azedarach leaves extract against Odontotermes obesus and Microtermes obesi. Int. J. Biosci., 6:
120-127. https://doi.org/10.12692/ijb/6.2.120-127

Qureshi, N.A., Qureshi, M.Z., Ali, N., Athar, M., AzizUllah, 2012. Protozoidal activities of Eucalyptus cammeldulensis, Dalbergia sissoo and Acacia arabica woods and their different parts on the entozoic flagellates of Heterotermes indicola and Coptotermes heimi. Afr. J. Biotechnol., 11: 12094-12102.

Saljoqi, A.R., Khan, M.A., Zell-e-Huma, Sattar, A., Misbah-Ullah and Khan, F., 2012. Behavioral changes of Heterotermes indicola (Isoptera: Rhinotermitidae) against some natural products. Pakistan J. Zool., 44: 1613-1622.

Wheeler, D.A. and Isman, M., 2001. Antifeedant and toxic activity off Trichilia americana extract against the larvae of Spodoptera litura. Ent. Exp. Appl., 98: 9-16. https://doi.org/10.1046/j.15707458.2001.00751.x

Zhao, B., Grant, G.G., Langevin, D. and MacDonald, L., 1998. Deterring and inhibiting effects of quinolizidine alkaloids on the spruce budworm (Lepidoptera: Tortricidae) oviposition. Environ. Ent., 27: 984-992. https://doi.org/10.1093/ ee/27.4.984 